\title{
TINGKAT KESEJAHTERAAN PETANI IKAN KERAPU CANTANG (Epinephelus sp) DI DESA LABUHAN KECAMATAN BRONDONG KABUPATEN LAMONGAN
}

\author{
PROSPERITY LEVEL FARMER GROUPER FISHERIES (Epinephelus sp) \\ IN LABUHAN VILLAGE, BRONDONG DISTRICT, LAMONGAN REGENCY
}

\author{
Wachidatus Sa'adah*, Khiqotul Milah \\ Fakultas Perikanan Universitas Islam Lamongan \\ *Email:wachidaafandi@gmail.com \\ (Diterima 26-12-2019; Disetujui 16-01-2020)
}

\begin{abstract}
ABSTRAK
Ikan kerapu merupakan salah satu komoditas unggulan untuk ekspor. Dengan berbudidaya ikan kerapu maka pendapatan yang diperoleh akan dimanfaatkan untuk mencukupi kebutuhan keluarga, agar tingkat kesejahteran keluarga meningkat. Penelitian ini dilakukan dengan tujuan untuk mengetahui pendapatan dan tingkat kesejahteraan petani ikan kerapu cantang. Penelitian ini dilaksanakan di Desa Labuhan Kecamatan Brondong Kabupaten Lamongan. Metode yang digunakan adalah metode kuantitatif dan kualitatif. Hasil penelitian menyatakan bahwa pendapatannya menguntungkan dan tingkat kesejahteraan para petaninya dikategorikan pada keluarga sejahtera tahap III plus.
\end{abstract}

Kata kunci: Ikan Kerapu Cantang, Pendapatan, Kesejahteraan.

\section{ABSTRACT}

Grouper fish is one of the leading commodities for export. With grouper cultivation, the income earned will be used to meet family needs, so that the level of family welfare increases. This research was conducted with the aim to find out the income and welfare level of the grouper cantang fish farmers. This research was conducted in Labuhan Village, Brondong District, Lamongan Regency. The method used is quantitative and qualitative methods. The results of the research stated that the income was profitable and the welfare level of the farmers was categorized as phase III plus welfare families.

Keywords: Cantang grouper fish, income, welfare.

\section{PENDAHULUAN}

Ikan kerapu cantang (Epinephelus $s p)$ merupakan salah satu komoditas perikanan yang mempunyai peluang yang baik di pasar dalam negeri dan luar negeri. Ikan kerapu mempunyai sifat-sifat yang menguntungkan untuk di budidayakan karena pertumbuhan yang cepat dan dapat di produksi massal untuk melayani permintaan pasar ikan kerapu dalam keadaan hidup. Data BPS menunjukan bahwa komoditas ikan kerapu hidup masuk dalam 20 jenis komoditas utama ekspor ikan Indonesia pada tahun 2016, dengan total nilai ekspor mencapai 32,18 juta US \$ atau sekitar 4,01 juta ekor. Negara tujuan ekspor kerapu adalah Hongkong, 
Malaysia, Vietnam dan China (Suhana, 2017).

Sedikitnya ada tiga alasan mengapa ikan kerapu perlu dikembangkan sebagai komoditas unggulan di Indonesia yang pertama, kerapu merupakan komoditi perikanan yang memiliki peluang ekspor yang sangat menarik yang selama ini belum dimanfaatkan secara penuh. Kedua pertumbuhan bisnis kerapu secara keseluruhan diharapkan akan membawa dampak peningkatan devisa negara dan kesejahteraan masyarakat lapisan bawah yang hidup dengan mata pencarian bidang perikanan. Ketiga modernisasi penangkapan dan budidaya ikan kerapu akan mengurangi dampak negatif terhadap lingkungan laut khususnya rusaknya terumbu karang. Alasan tersebut menunjukkan bahwa betapa pentingnya pengembangan perikanan ikan kerapu yang nantinya diharapkan tidak hanya memberikan dampak terhadap sektor perikanan secara luas melainkan juga terhadap pengembangan wilayah pariwisata dan pemberdayaan masyarakat.

Negara Indonesia merupakan negara yang berkembang dimana tingkat ekonominya rata-rata berada di bagian menengah kebawah. Pada tahun 2016 yang baru bisa dikatakan mampu atau layak dengan kehidupannya baru sekitar $20 \%$. Adapun salah satu yang menjadikan acuhan atau faktor utama adalah pendapatan. Yang mana bila pendapatan naik maka tingkat kesejahteraannya pun akan membaik. Dalam mengetahui tingkat kesejahteraannya bisa diukur dengan pendapatan yang diperoleh, pendidikan, kesehatan, aset kekayaan dan jabatan dalam lingkungan masyarakat.

Persentase penduduk miskin di Kabupaten Lamongan juga mengalami penurunan dari 15,38\% pada bulan Maret 2015 menjadi sebesar $14,89 \%$ pada bulan Maret 2016. Sehingga sejak 2008-2016, baik jumlah maupun persentase penduduk miskin di Kabupaten Lamongan selalu berkurang setiap tahunnya (BPS Lamongan). Sejahteranya suatu keluarga salah satunya bisa diketahui dari tingkat pendapatan. Pendapatan yang mempunyai pengaruh besar dalam menentukan tingkat kesejahteraan suatu keluarga. Sedangkan sejahtera itu bukan saja dipengaruhi oleh adanya pendapatan melainkan juga jumlah anggota, umur kepala keluarga, dan umur anggota keluarga. Dengan adanya ciri-ciri tingkat kesejahteraan maka akan membentuk suatu kelas sosial atau stratifikasi sosial. Di Desa Labuhan kebanyakan penduduknya bekerja sebagai petani ikan 
kerapu, yang mana pendapatan utamanya berasal dari hasil budidaya yang dikerjakan oleh keluarganya. Pendapatan budidaya yang diperolehnya per siklus sekali dalam satu tahun, sehingga dalam pengelolaan keuangan harus sebaik mungkin agar semua keinginan dan kebutuhan dapat terpenuhi serta sejahtera.

.Dikatakan sejahteranya suatu rumah tangga itu bisa di ukur dengan aset kekayaan yang didapatkan. Para petani ikan kerapu di Desa Labuhan tergolong masyarakat yang sejahtera, karena disamping mendapatkan pendapatan yang lebih baik untuk kebutuhannya secara finansial juga secara non-finansial. Kebutuhan finansial bisa dirasakan atau bersentuhan langsung dengan kebutuhan jasmani. Adapun untuk kebutuhan nonfinansial dapat dirasakan dengan kesenangan atau ketenangan batin. Sejahteranya seseorang bisa dirasakan baik secara jasmani dan rohaninya. Kesejahteraan seseorang juga bisa dilihat dari jumlah aset kekayaan yang dimiliki, pendidikan, kesehatan, kedudukan dalam masyarakat dan pendidikan serta moral anak atau anggota keluarga.

Berdasarkan latar belakang diatas, maka tujuan dari penelitian ini adalah untuk mengetahui pendapatan dan tingkat kesejahteraan petani ikan kerapu di Desa
Labuhan Kecamatan Brondong Kabupaten Lamongan.

Hasil penelitian terdahulu menurut Erni (2015), bahwa pengeluaran keluarga nelayan bagan sebagian besar masih digunakan untuk pengeluaran pangan. Sebagian besar nelayan bagan sudah termasuk dalam kategori sejahtera berdasarkan 14 kriteria rumah tangga miskin penerima BLT dan tidak ada yang memiliki pendapatan di bawah garis kemiskinan Kabupaten Kotabaru. Menurut Hartoyo (2010) bahwa pada kelompok pembudidaya ikan, kepala keluarga lebih banyak memiliki pekerjaan sampingan selain pekerjaan utamanya sebagai pembudidaya ikan. Pendapatan dan pengeluaran per kapita perbulan pada kelompok pembudidaya ikan cenderung lebih tinggi dibanding dengan kelompok non pembudidaya ikan

\section{METODE PENELITIAN}

Metode yang digunakan dalam penelitian ini adalah metode kuantitatif dan kualitatif dengan pengambilan sampel dengan simple random sampling yang digunakan apabila karakteristik atau ciri dari anggota adalah populasi sama (homogen) (Azuar Juliandi, 2014). Pertimbangan memilih metode simple random sampling dikarenakan jumlah 
populasi petani ikan kerapu cantang sistem intensif sebanyak 95 petani, sehingga pengambilan sampelnya dilakukan secara random. Dari jumlah tersebut kemudian dipilih 5 petani atas dasar karakteristik dari luas lahan dan status kepemilikan lahan, yang masingmasing diwakili oleh satu petani sehingga ditemukan jumlah sampel 5 petani,

Teknik pengumpulan data yang digunakan terdiri atas data primer dan data sekunder. Data primer diperoleh dengan cara pengamatan langsung ke lapangan, wawancara, dokumentasi, dan angket Sedangkan data sekunder diperoleh melalui bacaan, literatur, dan lain-lain.

\section{HASIL DAN PEMBAHASAN}

\section{Asal Mula Berbudidaya Ikan Kerapu}

\section{di Desa Labuhan}

Pada awal tahun 2000 di Desa

Labuhan mulai dilaksanakannya budidaya ikan kerapu jenis kerapu cantik yang saat itu menjanjikan untuk dibudidayakan oleh masyarakat setempat. Budidaya ikan kerapu cantik bertahan selama 7 tahun kemudian beralih ke jenis ikan kerapu lumpur pada tahun 2007. Alasan beralihnya ke jenis lain karena mengalami penurunan harga. Berbeda dengan jenis ikan kerapu lumpur yang memiliki keunggulan untuk dibudidayakan karena cepat besar dengan kurun waktu budidaya 8 bulan dengan bobot rata-rata minimal 500 gram. Kemudian pada tahun 2011 masyarakat setempat beralih membudidayakan ke jenis lain yaitu ikan kerapu tiger. Alasan beralihnya karena banyak tengkulak yang menawarkan dengan harga tinggi, Selanjutnya pada tahun 2015 sampai sekarang, masyarakat setempat membudidayakan jenis ikan kerapu cantang/hybrid. Jenis ikan ini merupakan hasil persilangan dari ikan kerapu macan dan kerapu lumpur.

Dengan Luas lahan tambak ikan kerapu cantang sekitar 47 ha, dan hasil panen bisa mencapai 6 ton/ha dalam jangka waktu delapan bulan, masyarakat mampu menyumbang produksi kerapu di Kabupaten Lamongan mencapai 150-200 ton/tahun. Konsumen ikan kerapu cantang ada yang dari dalam negeri dan luar negeri, adapun dalam negeri yaitu Bali, Surabaya, dan Jakarta dengan harga yang ditawarkan sekitar Rp95.000$105.000 / \mathrm{kg}$, sedangkan dari luar negeri yaitu Malaysia dan Singapura dengan harga yang ditawarkan sekitar Rp250.000-350.000/kg. 


\section{Pendapatan}

Budidaya ikan adalah usaha untuk memelihara ikan, kegiatan ini bisa menambah nilai ekonomis pada harga ikan baik untuk konsumsi atau untuk hiasan. Salah satu tujuan dari budidaya adalah untuk menghasilkan uang yang biasa disebut dengan pendapatan.

Kelompok petani ikan kerapu di Desa Labuhan rata-rata pendapatan bersihnya debih dari Rp100.000.000/siklus/tahun. Setiap siklusnya membutuhkan waktu sekitar 8 bulan, mulai dari persiapan lahan sampai panen. Kegiatan budidaya ini sebagian besar merupakan pekerjaan utama dari masyarakat setempat.

Pendapatan dari masing-masing petani itu diperoleh dari penerimaan dari penjualan ikan dikurangi dengan biayabiaya produksi dari persiapan tambak sampai panen. Setiap petani ikan kerapu cantang di Desa Labuhan memperoleh pendapatan antara Rp100.0000.000Rp500.000.000. Untuk pendapatan dari masing-masing petani ikan kerapu cantang dapat dilihat pada Tabel 1 .

Tabel 1. Pendapatan Para Petani Ikan Kerapu Cantang di Desa Labuhan Kecamatan Brondong Kabupaten Lamongan

\begin{tabular}{ccrrrr}
\hline Petani & $\begin{array}{c}\text { Luas Lahan } \\
\text { (ha) }\end{array}$ & $\begin{array}{c}\text { Biaya Tetap (Juta } \\
\text { Rp) }\end{array}$ & $\begin{array}{c}\text { Biaya Variabel } \\
\text { (Juta Rp) }\end{array}$ & $\begin{array}{c}\text { Penerimaan (Juta } \\
\text { Rp) }\end{array}$ & $\begin{array}{c}\text { Pendapatan (Jura } \\
\text { Rp) }\end{array}$ \\
\hline 1 & 1,5 & 11,170 & 228,080 & 637,500 & 398,250 \\
2 & 1,2 & 12,635 & 314,650 & 586,500 & 254,215 \\
3 & 1 & 9,242 & 260,180 & 476,000 & 206,578 \\
4 & 1 & 14,269 & 267,700 & 561,000 & 279,031 \\
5 & 0.8 & 14,502 & 203,680 & 357,999 & 138,818 \\
\hline
\end{tabular}

Sumber: Data Primer Terolah, 2019

Jika dilihat pada Tabel 1 dapat dijelaskan bahwa pendapatan dari petani ikan kerapu cantang yang tertinggi adalah pada petani 1 dengan luas lahan 1,5 ha sebesar Rp398,250,000, sedangkan pendaptan yang terendah adalah pada petani 5 dengan luas lahan 0,8 ha. Sehingga dapat disimpulkan bahwa semakin luas kepemilikian lahan semakin besar pendapatannya dan sebaliknya.

\section{Pengeluaran}

Setiap manusia memiliki kebutuhan yang berbeda-beda, mulai dari gaya hidup, selera dan kebiasan. Berdasarkan kebutuhan tersebut, maka banyak cara pula yang akan dilakukan untuk memenuhinya. Mulai dari menejemen keuangan yang baik untuk keluarga supaya dapat hidup dengan sejahtera 
untuk memenuhi kebutuhan jasmani maupun rohani.

Perolehan pendapatan dari hasil budidaya ikan kerapu cantang akan mereka kelola dan dialokasikan untuk kebutuhan dan keinginan. Alokasi kebutuhan digunakan untuk operasional sehari-hari, sedangkan alokasi keinginan untuk investasi berupa tanah, kendaraan bermotor, dan menabung.

Pengeluaran berdasarkan kebutuhan dan keinginan para petani ikan kerapu cantang dapat dilihat pada Tabel berikut.

Tabel 2. Pengeluaran Para Petani Ikan Kerapu Cantang di Desa Labuhan Kecamatan Brondong Kabupaten Lamongan

\begin{tabular}{cccrrrrr}
\hline Petani & $\begin{array}{c}\text { Konsumsi } \\
\text { (Jut Rp) }\end{array}$ & $\begin{array}{c}\text { Tanggungan } \\
\text { Keluarga (Juta Rp) }\end{array}$ & $\begin{array}{c}\text { Pendidikan } \\
\text { (Juta Rp) }\end{array}$ & $\begin{array}{c}\text { Sosial } \\
\text { (Juta Rp) }\end{array}$ & $\begin{array}{c}\text { Hiburan } \\
\text { (Juta Rp) }\end{array}$ & $\begin{array}{c}\text { Ciciclan } \\
\text { (Juta Rp) }\end{array}$ & $\begin{array}{c}\text { Jumlah } \\
\text { (Juta Rp) }\end{array}$ \\
\hline 1 & 73,200 & 33,600 & 2,001 & 2,500 & 2,000 & & 113,300 \\
2 & 68,400 & 63,600 & 12,001 & 2,500 & 2,000 & & 148,500 \\
3 & 61,200 & 48,000 & 9,001 & 2,500 & 2,000 & & 122,700 \\
4 & 73,200 & 38,700 & 1,201 & 2,000 & 2,000 & 4,000 & 201,100 \\
5 & 63,000 & 48,000 & 5,001 & 2.500 & 2,000 & & 120,500 \\
\hline
\end{tabular}

Sumber: Data Primer, 2019

Pada Tabel 2 dapat dijelaskan bahwa pengeluaran dari para petani meliputi konsumsi, tanggungan keluarga, pendidikan, sosial, hiburan, dan cicilan. Jumlah pengeluaran terbesar ada pada petani 4, karena terdapat pengeluaran untuk cicilan, yang tidak ada pada petani lain.

\section{Tingkat Kesejahteraan Petani Ikan Kerapu Cantang}

Banyak dari petani ikan kerapu cantang ini yang menggunakan pendapatannya lebih kepada kebutuhan dari pada keinginan, ada pula yang memprioritaskan untuk masa depan, dan ada pula yang memprioritaskan pendidikan anaknya sehingga kebutuhan untuk konsumsi dikurangi. Adapun aset kekayaan yang dimiliki oleh petani ikan kerapu cantang berupa tabungan, investasi tanah, hewan peliharaan, kesehatan, pendidikan, dan rekreasi yang kesemuanya itu mencerminkan tingkat kesejahteraannya. Untuk mengetahui tingkat kesejahteraan dari para petani ikan kerapu cantang dapat dilihat pada Tabel 3. 
Tabel 3. Tingkat Kesejahteraan Keluarga Petani Ikan Kerapu Cantang di Desa Labuhan di Kecamatan Brondong

\begin{tabular}{|c|c|c|}
\hline Petani & Kategori Tingkat Kesejahteraan & Keterangan \\
\hline 1 & Keluarga sejahtera tahap III plus & $\begin{array}{l}\text { - Memiliki tabungan baik deposito atau non-deposito. } \\
\text { - Memiliki tanah seluas } 200 \mathrm{~m}^{2} \text {. } \\
\text { - Kondisi jasmani anggota keluarga dalam keadaan sehat. } \\
\text { - Mempunyai tanggungan pendidikan } 1 \text { anak sekolah PAUD. } \\
\text { - Rekreasi keluarga dilaksanakan } 2 \text { kali setahun }\end{array}$ \\
\hline 2 & Keluarga sejahtera tahap III plus & $\begin{array}{l}\text { - Memiliki tabungan deposito atau non- deposito. } \\
\text { - Memiliki tanah seluas } 375 \mathrm{~m}^{2} \text {. } \\
\text { - Kondisi jasmani anggota keluarga dalam keadaan sehat. } \\
\text { - Mempunyai tanggungan pendidikan } 3 \text { anak sekolah SD, } \\
\text { - SMA, dan kuliah. } \\
\text { - Rekreasi keluarga dilaksanakan } 2 \text { kali setahun }\end{array}$ \\
\hline 3 & Keluarga sejahtera tahap III plus & $\begin{array}{l}\text { - Memiliki tabungan deposito atau non- deposito. } \\
\text { - Memiliki tanah seluas } 200 \mathrm{~m}^{2} \text {. } \\
\text { - Kondisi jasmani anggota keluarga dalam keadaan sehat. } \\
\text { - Mempunyai tanggungan pendidikan } 2 \text { anak sekolah SMA, dan } \\
\text { - kuliah. } \\
\text { - Rekreasi keluarga dilaksanakan } 2 \text { kali setahun }\end{array}$ \\
\hline 4 & Keluarga sejahtera tahap III plus & $\begin{array}{l}\text { - Memiliki tabungan deposito atau non- deposito. } \\
\text { - Memiliki tanah seluas } 375 \mathrm{~m}^{2} \text {. } \\
\text { - Kondisi jasmani dalam keadaan sehat. } \\
\text { - Mempunyai tanggungan pendidikan } 1 \text { anak sekolah SD. } \\
\text { - Rekreasi keluarga dilaksanakan } 2 \text { kali setahun }\end{array}$ \\
\hline 5 & Keluarga sejahtera tahap III plus & $\begin{array}{l}\text { - Memiliki tabungan deposito atau non- deposito. } \\
\text { - Memiliki tanah seluas } 150 \mathrm{~m}^{2} \text { dan } 2 \text { sapi brahma. } \\
\text { - Kondisi jasmani anggota keluarga dalam keadaan sehat. } \\
\text { - Mempunyai tanggungan pendidikan } 4 \text { anak sekolah SD, SMP, } \\
\text { SMA, dan kuliah. } \\
\text { - Rekreasi keluarga dilaksanakan } 2 \text { kali setahun. }\end{array}$ \\
\hline
\end{tabular}

Sumber: Data Primer Terolah, 2019

Tabel 3 menunjukkan bahwa tingkat kesejahteraan dari para petani ikan kerapu cantang masuk dalam kategori keluarga sejahtera tahap III plus yaitu tingkat kesejahteraan dimana setiap kebutuhan baik yang bersifat jasmani atau rohani telah terpenuhi oleh keluarga.

\section{KESIMPULAN DAN SARAN}

Pendapatan dari 5 petani ikan kerapu cantang adalah sebagai berikut: untuk petani 1 sebesar Rp398.250.000; petani 2 sebesar Rp 259.215.000; petani 3 sebesar Rp 206.578.000; petani 4 sebesar Rp 279.031.000; dan petani 5 sebesar Rp 138.818.000. 
Adapun untuk tingkat kesejahteraan dari 5 petani ikan kerapu cantang termasuk pada kategori keluarga yang sejahtera pada tahap III plus, yaitu tingkat kesejahteraan dimana setiap kebutuhan baik yang bersifat jasmani atau rohani telah terpenuhi.

Saran untuk penelitian ini adalah agar petani ikan kerapu cantang tetap mempertahankan hasil yang diperoleh dengan cara lebih memperhatikan proses produksinya agar memperoleh hasil yang menguntungkan sehingga semakin meningkat kesejahteraannya. Peran serta pemerintah sangat penting dalam rangka meningkatkan kualitas sumberdaya petani ikan kerapu cantang melalui kegiatan penyuluhan tentang teknologi budidaya ikan, agar pengetahuan tentang terjangkaunya harga benih ikan yang dirasa cukup mahal bagi para petani. Bagi para petani hendaknya mengatur keuangan lebih baik lagi dengan memperioritas kebutuhan yang penting terlebih dahulu.

\section{DAFTAR PUSTAKA}

BKKBN. (2014). Pedoman Tata Cara Pencatatan dan Pelaporan Pendataan keluarga. Sumatera Utara. Badan Koordinasi keluarga Berencana Nasional.

Elmanora, Muflikhati, I, \& Alfiasari. (2012). Keluarga Petani
Kayumanis. Jurnal Ilmu Keluarga dan Konsumen, 5(1), 58-66.

Hartoyo. (2010). Faktor-faktor yang Mempengaruhi Kesejahteraan Keluarga.

Iskandar, A. (2007). Analisis Praktik Manajemen Sumberdaya Keluarga dan Dampaknya Terhadap Kesejahteraan Keluarga di Kabupaten dan Kota Bogor (Disertasi). Sekolah Pascasarjana, Institut Pertanian Bogor, Bogor.

Juliandi, Azuar dkk. (2014). Metodologi Penelitian Bisnis Konsep dan Aplikasi. Umsu Press, Medan

Rizkya, M. (2012). Pembenihan Ikan Kerapu Cantang (Epinephelus sp). di Balai Perikanan Budidaya Air Payau (BPBAP) Situbondo, Jawa Timur. Sekolah Tinggi Perikanan, Bogor.

Sa'adah, Wachidatus. (2014). Analisa Finansial Usaha Ikan Rucah Di UD. Gendung $\mathrm{H}$ di Desa Brondong Kecamatan Brondong Kabupaten Lamongan. Jurnal Grouper, 5(2) 17-23.

Soekartawi. (2002). Analisis Usahatani. Universitas Indonesia, Jakarta.

Sukirno, Sadono (2005). Pengantar Mikro Ekonomi. PT Raja Grafindo, Jakarta.

Sunarti. (2006). Indikator Keluarga Sejahtera: Sejarah Pengembangan, Evaluasi, dan Keberlanjutannya. ID. IPB Press, Bogor.

Suratiyah, Ken. (2015). Ilmu Usahatani. Penebar Swadaya, Jakarta.

Widyaningsih, Erni. (2015). Alokasi Pengeluaran dan Kesejahteraan Keluarga pada Keluarga Nelayan Bagan.

Yusuf, Muri. (2017). Metode Penelitian Kuantitatif Kualitatif dan Penelitian Gabungan. Kencana Prenada Media Group, Jakarta. 